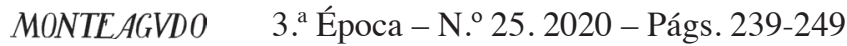

\title{
Policías Y guARdias: VISIÓn LITERARIA EN LA NUEVA NOVELA POLICÍACA ESPAÑOLA
}

\author{
EnCina Isabel LóPez MarTíNeZ \\ Universidad de Murcia
}

\section{RESUMEN:}

La nueva novela policíaca en España es actualmente uno de los géneros más consumidos y reconocidos por los lectores. Esto se debe a una serie de novedades que escritores como Alicia Giménez Bartett o Lorenzo Silva, entre otros, presentan en sus producciones. Entre ellas destaca la incorporación del detective a un cuerpo de seguridad oficial del Estado. Estos autores reflejarán la realidad de la Policía Nacional y de la Guardia Civil, respectivamente, ofreciendo una perspectiva literaria desconocida y desatendida hasta la fecha y que será, en estos momentos, fundamental para entender la construcción del detective y los temas principales del argumento.

\section{PALABRAS CLAVE:}

Novela policíaca; Detective; Policía; Narrativa española; Crimen.

\begin{abstract}
:
The new police novel in Spain is currently one of the most consumed and recognized genres by readers. This is due to some novelties that writers such as Alicia Giménez Bartett or Lorenzo Silva, among others, present in their productions. These include the incorporation of the detective into an official state security organism. These authors show the reality of the National Police and the Civil Guard, respectively, offering an unknown and unattended literary perspective to date and that is, at this time, essential to understand the construction of the detective personality and the main themes of the argument.
\end{abstract}

\section{KEYWORDS:}

Police novel; Detective; Police; Spanish narrative; Crime.

Hoy en día el panorama literario español asiste a una evidente eclosión de la novela policíaca. Este tipo de narraciones surge en época decimonónica en una Europa de incipiente industrialización, de la mano de Poe, Collins, Christie o Conan Doyle, y continúa su desarrollo al otro lado del Atlántico, años después, en la América sucia, oscura y con olor a pólvora de Chandler, Hammett o McCoy. España habrá de esperar hasta el final del franquismo para acoger entre sus fronteras a escritores que trasladasen la fórmula policíaca a la realidad de un país atrasado, constreñido y acomplejado tras una guerra civil y una dictadura. De la mano de Manuel Vázquez Montalbán y 
Eduardo Mendoza, principalmente, el género comienza a despegar poco a poco en nuestras letras. Estos autores, acompañados de García Pavón y seguidos de cerca por Juan Madrid, Andreu Martín o Martínez Reverte, entre otros, crearán detectives originales, acordes a los tiempos y a los ritmos de la sociedad española de finales de siglo XX. Las circunstancias, los temas, los ambientes o las vivencias se acercarán, cada vez más, al marco sociohistórico al que se vinculan, despegándose de complejos y limitaciones y siendo cada vez más capaces de trasladar a los lectores la crítica, la denuncia y el escaparate de una España en ciernes.

Así, a finales del siglo pasado y primeras décadas del presente, toma el testigo una nueva oleada de escritores, más modernos y modernizadores, que se adscriben a la fórmula preceptiva del género pero la matizan con importantes y señaladas novedades. Estas van a permitir su evolución, crecimiento y actualización, acercando a un público la realidad más reciente y actual. Nuevos temas, nuevos intereses, nuevos modos de contemplar el mundo, nuevas preocupaciones y motivaciones, nuevas circunstancias laborales del detective o nuevos modos de delinquir se darán cita entre las páginas de estos autores, ofreciendo un heterogéneo y amplio mosaico donde abunda la variedad, la amplitud de horizontes temáticos o la diversidad de personajes. Los nombres de los escritores que se dedican a esta nueva novela policíaca aumenta cada día, suponiendo un ingente torrente de novelas del género inundando librerías, estantes y páginas de periódicos.

Entre las evidentes novedades de este reciente relato detectivesco sobresalen tres, de las cuales, asimismo, derivarán diversas matizaciones. El detective, tradicionalmente concebido como un personaje de fuerte personalidad y carácter, algo atípico y peculiar, habitualmente marginal o desarraigado, excéntrico y solitario, abandonará ese ostracismo para acomodarse a una sociedad que también es la suya y en la que se siente cómodo, acogido y partícipe. Se trasladarán a las páginas las vivencias cotidianas, las costumbres y hábitos más humanos de su día a día, los gustos y las manías, las relaciones personales o familiares, las emociones, los sentimientos, las aficiones o los intereses más allá de lo detectivesco. Además, el protagonista dejará de trabajar en las sombras, sin orden ni ley como hasta ahora, para enfundarse el uniforme de un cuerpo de seguridad oficial. Este nuevo marco laboral delimitará su radio de acción, lo dotará de un equipo, lo subyugará a unas normas y a una ley, le despertará una moral y una ética del bien y del deber comunitario, y lo incorporará a un sistema jerarquizado donde ya no trabaja solo.

Pero no me extenderé más sobre estas miserias que padezco como miembro subalterno de un cuerpo jerarquizado y militar, porque siempre que trato con ellas me acuerdo de esos olímpicos detectives de las novelas que hacen lo que se les pone en las narices sin rendir nunca cuentas a nadie y me siento como un paria (Silva, 2005: 363). 
Por último, y derivado de esta nueva realidad laboral, será común encontrar en esta novela no ya a un único protagonista, hegemómico y claro vórtice del relato, sino que tendrá a su lado a un coprotagonista, una pareja detectivesca que se convertirá, a su vez, en un compañero de vida, en un amigo y en un confidente. De este modo, la vida privada e íntima de los personajes será a menudo compartida, llegando al lector con fluidez, como hasta entonces era difícil que lo hiciera. Todo este conjunto de novedades determinarán una nueva realidad social, laboral y personal del personaje, ofreciendo múltiples perspectivas de variados asuntos con las que se aliñan las aventuras meramente policíacas. De entre estas sobresale una hasta entonces impensable: la que concierne a la visión literaria de estos cuerpos y fuerzas de seguridad del Estado.

Sin lugar a dudas, los detectives protagonistas deben ocupar el grueso del análisis de la nueva novela policíaca, precisamente por ser el corazón de esta, por atesorar a su alrededor situaciones, pensamientos y acciones que determinarán el cauce por el que la trama se desarrolle, y por presentar unas singulares características que permiten definir y encuadrar este tipo de narraciones. A lo largo de la tradición del subgénero policíaco el investigador ha desempeñado su labor con una importante dosis de individualismo e independencia. Bien en la novela clásica o bien en la negra, el personaje responde a una ambicionada demarcación y a la ostentación y aprovechamiento de una libertad facilitada por la realidad social e histórica del período, o por elección propia.

El nacimiento del detective privado permitió subsanar el vacío legal ocasionado por la rápida gestación de las nuevas sociedades modernas, donde se dio un aglutinamiento voraz en las ciudades y ante el cual los gobiernos encontraron serias dificultades para su organización. La delincuencia y el crimen, en consecuencia, se cuelan en este momento por los amplios resquicios que dejan unas ciudadanías en ciernes, entre las piezas del puzle urbano que trata de dar forma a la insólita concepción vital del hombre del siglo XX.

En este caótico panorama, innovador y desconocido para el hombre mundano pero también para el gobernante, debe reducirse con presteza la escalada de violencia que pone en peligro la estabilidad, el desarrollo y el avance hacia la modernidad que experimenta el mundo europeo y americano. Surgen, de esta manera, los primeros cuerpos policiales, con la perspicua misión de consagrarse al orden, al equilibrio y a la paz de estas heterogéneas comunidades. No obstante, estos organismos carecen aún de formación, de estructura, de disciplina interna y de autoridad externa, por lo que necesitarán todavía años para manejar con seguridad y firmeza la potestad que se les presupone. Hasta que llegue ese momento, el crimen continúa anegando las calles de las grandes ciudades, los malhechores campan a sus anchas, los delitos se 
cometen a plena luz del día y el miedo a las sombras y a los rincones acongoja a la población. Aparece, entonces, un nuevo héroe: el detective privado, capaz de plantar cara directamente al mal y salir victorioso.

Este será, ni más ni menos, que un ciudadano normal, cuyo mérito y poder reside precisamente en saber desenvolverse con soltura y maestría por ambientes y lugares a los que no llegan las recién instauradas policías oficiales. La capacidad del detective residirá, además de en una estupenda intuición y en ciertas dotes deductivas, en conocer de primera mano, como hombre moderno habitante de la ciudad, los entresijos más ocultos de esta.

En este momento la Policía se ve como un órgano pueril e ineficaz, insuficiente para abordar la verdadera raíz del problema, para atacar con firmeza y contundencia al criminal, más preocupada de airear una imagen de eficiencia y seguridad aún lejana a la realidad. Habrán de pasar años y décadas para que, poco a poco, la regulación de estas instituciones se asiente, se acomode y se encaje, permitiendo encarar al crimen en igualdad de condiciones, con hombres formados, competentes y con medios suficientes.

Además de la mera consideración funcional de los cuerpos de seguridad, es menester asimismo reparar en cuestiones de índole histórica. A menudo se ha entendido la labor desempeñada por estas entidades como una inherente constricción de los derechos del pueblo. La frontera que separa la necesidad de seguridad de la limitación de la libertad ha ocasionado, con frecuencia, tiranteces y tensiones entre la ciudadanía y las fuerzas del orden. A esto hay que sumar, además, la tendencia lógica de gobiernos y administraciones a recurrir instantáneamente a órganos policiales y militares para pretender, mantener o luchar por el poder político, a costa del dimanado perjuicio para la población civil.

Estas coyunturas determinan que en la mentalidad popular sea habitual encontrar ciertas reticencias y suspicacias para con los cuerpos de seguridad de un país. Este pensamiento, que nace con los primeros pasos titubeantes de las policías - rebasados además ampliamente por la mayor capacidad de resolución del detective privado - florece y se consolida al contemplar el papel que estos organismos toman en guerras y conflictos, donde defienden los intereses del gobierno desdeñando a menudo al pueblo llano.

Todo ello desemboca en una tangible cautela y en un perseverante rechazo que no favorece el retrato literario del personaje policía, pero sí da la oportunidad de engrandecer, en consecuencia, la figura del investigador particular. Frente al primero, este será ejemplo de un hombre normal cuyas motivaciones e ideales no se deben a las imperantes en un gobierno que quizá no concuerda con su pueblo, sino que trabaja por y para el ciudadano, su único soberano. El detective privado no debe rendir 
cuentas a la ley ni a la norma, es ajeno a problemas políticos e históricos y limita su círculo de acción al caso que le atañe. Esto supone, además, una implícita y evidente crítica para con el poder oficial, ya que estos investigadores demostrarán que están por encima de organismos presuntamente mucho más preparados y con más medios a su alcance.

En el hecho literario esto da pie, en primer lugar, a un mayor número de posibilidades en la narración. Mientras que la Historia debe ceñirse a la verdad, la Literatura lo hace a lo verosímil. Construir una trama donde un detective privado desentrañe, luche, persiga y resuelva crímenes ficticios pero plausibles sirve, por un lado, para mostrar esa nueva sociedad donde el individuo es la herramienta idónea para llevar a cabo con éxito tareas presuntamente destinadas a una entidad mucho más poderosa y formada. Por otro, abandera una sutil pero lacerante crítica a una autoridad insuficiente, lejana al ciudadano, reducida a intereses y esferas de políticos y gobernantes.

Todo ello acaba confluyendo en que se desdeñe la posición del detective como miembro de los cuerpos de seguridad y, si se hace - ejemplo del francés Vidocq-, sea de modo más circunstancial y anecdótico, pues en definitiva el protagonismo absoluto residirá en el sujeto como individuo, en la figura independiente, y no tanto en su realidad como miembro del sistema. En los albores del género son ejemplo paradigmático del héroe solitario el Sherlock Holmes de Doyle, el padre Brown de Chesterton, el Hércules Poirot de Christie, o los americanos Sam Spade, Philip Marlowe o Race Williams, de Hammett, Chandler y Daly, respectivamente. En nuestro país destacan, entre otros, Pepe Carvalho, Toni Romano o Julio Gálvez de la mano de Vázquez Montalbán, Juan Madrid y Jorge Martínez Reverte.

En la tradición española este pensamiento será fácilmente observable. Las huellas de un convulso siglo XX - marcado por conflictos internos de poder, dictaduras y abusos de la autoridad - dificultan contemplar a un héroe literario en uno de esos organismos, cuyo desempeño habitual se acerca más a la opresión y a la violencia que a la defensa justa, ecuánime y desinteresada del bien social.

No se dará hasta años después del fin de la guerra civil — cuando la memoria histórica calme pavores y deje cerrar heridas - el momento en que, por fin, algunos escritores españoles se atrevan retratar el Cuerpo Nacional de Policía o a la Guardia Civil desde dentro, sin tapujos, con realismo y documentación, acercando al lector una dimensión desconocida y temida. Las novelas policíacas precedentes, como las escritas por Vázquez Montalbán, Juan Madrid o Andreu Martín, aun desempeñando ya un papel vital para abrir camino al género, todavía evocan a detectives construidos a la vieja usanza: seres individuales, independientes, trabajadores por cuenta propia, reticentes al trato con el orden y sin más ley que la propia. 
El precedente más claro e icónico en nuestra literatura del detective policía es el guardia municipal de Tomelloso, Plinio, ideado por Francisco García Pavón. El propio Lorenzo Silva ve en el escritor manchego al iniciador y guía de esta nueva concepción del héroe policíaco: «El primero que tuvo el coraje de sacudirse los complejos fue García Pavón. Él es el precursor, con su Policía municipal y sus crímenes de pueblo» (apud Morán, 2013).

Plinio se postula, pues, como el primer detective perteneciente a un órgano oficial de la literatura de nuestro país caracterizado como típicamente español (Godón Martínez, 2005). Su modo de vida rural, su labor detectivesca encuadrada en un marco alejado de la ciudad y sus hábitos poco elitistas y austeros lo acercan a la realidad del lector, a la sociedad del momento, a las preocupaciones y a los asuntos que mueven, en ese período, al pueblo español. De la misma forma, detectives de la actualidad, como Delicado o Bevilacqua, aun salvando las distancias marcadas por la época y el espacio, retratan con su modo de vida y la labor que desempeñan el mundo en el que se mueven. El cronotopo de Plinio es el Tomelloso de los años veinte, que se extrapola a su vez a toda la sociedad española (marcadamente rural) de la época en general. El cronotopo de Bevilacqua y de Delicado es la realidad actual en el marco de una gran ciudad (Madrid y Barcelona, respectivamente), pero asimismo reflejo global de la idiosincrasia colectiva del tiempo presente, movible a cualquier punto de nuestra geografía.

Serán, pues, escritores como Alicia Giménez Bartlett o Lorenzo Silva, en primer lugar, los que den un paso más allá, atreviéndose a desnudar por completo las entrañas del Cuerpo Nacional de Policía y de la Guardia Civil, respectivamente, a través del testimonio y retrato de sus personajes. Una vez derrumbado el muro de los prejuicios, los tabués y las idealizaciones, la estela de escritores que engendran en los últimos tiempos detectives amparados en estos organismos se multiplica. Si bien Giménez Bartlett y Silva descorchan la botella, hoy cabe hablar de una extensa nómina de herederos continuadores de esta exitosa fórmula: Dolores Redondo retrata la Policía Foral de Navarra; Rafa Melero, Teresa Solana y Toni Hill visten a sus protagonistas con el uniforme de los Mossos d'Esquadra, y Domingo Villar, entre otros, imagina a un inspector de la Policía Nacional. El propio Lorenzo Silva afirma que:

los guardias civiles son unos profesionales que estaban casi inéditos como personajes pero son un chollo para la ficción. Hay una realidad desconocida y valiosa ahí. La Guardia Civil lleva 174 años defendiendo el bien común, que en España no es de nadie (apud Galindo, 2018). 
Policías y guardias: visión literaria en la nueva novela policíaca española

Con la creación de estos investigadores se cumple un objetivo social, más allá de lo puramente literario. El lector accede a un mundo habitualmente extraño y ajeno, aún manchado de prejuicios y ajados recelos, enquistados en la mentalidad popular al asociar a estas entidades con la opresión, con el brazo armado del dominio político o con la tendencia al atropello desmedido e injustificado. La cercanía de unos personajes inspirados en hombres y mujeres reales - con virtudes terrenales y defectos comprensibles, sin poderes extraordinarios y trabajadores natos- legitima al lector conocer los medios, los fines y los métodos que como policías hoy en día, en nuestras calles, los definen y acotan. La opacidad que envuelve a estas organizaciones se atenúa, dejando entrever una normalización del sistema y de los que para él trabajan. Se trata de individuos también imperfectos, con una vida personal en la que aciertan y yerran, en la que acarrean conflictos y triunfos, y de la que disfrutan y sufren como cualquier ser humano.

El propio Bevilacqua debe combatir viejos tópicos del haber popular sobre su condición de guardia en algún episodio, como el siguiente pasaje de la séptima novela de la serie, Los cuerpos extraños:

- Primer movimiento de la Quinta de Mahler. He de reconocer que no es el tono que habría esperado del móvil de un guardia.

De gente como Grau me fastidiaba, no lo ocultaré, aquella clase de comentario, que presuponía sistemáticamente que, por haberme encajado alguna vez un tricornio en el cráneo, el contenido de este era exiguo o carecía de la variedad corriente en alguien de mi tiempo y lugar. Pasaba con las lecturas, con la música, hasta con los idiomas. Y podía entender que no hacía demasiadas décadas el Cuerpo había estado formado sobre todo por gentes rústicas, y que incluso hubo una época oscura, en los cuarenta del pasado siglo, en que se coló algún analfabeto, pero era pasmoso que en pleno S. XXI a algunos, o a muchos, el reloj les siguiera dando esa hora, cada vez más lejana (Silva, 2014: 223).

También Petra Delicado sufre los prejuicios velados para con su profesión, los viejos clichés y temores arrastrados socialmente que aún manchan la imagen del policía, en este caso cuando sus compañeras de gimnasio se enteran de a qué se dedica: «Me quedé helada. Nunca había comentado nada con ellas sobre mi profesión. Decir que eres policía suele ser suficiente para que se forme a tu alrededor un halo de desconfianza» (Giménez Bartlett, 1996: 70).

Esta preocupación es visible esencialmente en la vida privada de los detectives, donde salen a relucir estigmas obsoletos y subyacente interés malicioso por su profesión. Es elocuente, asimismo, la impresión y la cierta incomodidad que le produce a Petra el plan de una cena formal con los amigos arquitectos de su marido: 
De modo que seguí preocupándome un rato más. Estaba convencida de que muchos de los colegas de mi marido sabían que era policía y me mirarían con expectación. ¿Por qué un policía excita la curiosidad de la gente más que ningún otro oficio? ¿Porque tenemos fama de estar encallecidos y ser un poco cabrones? ¿Porque nos ocupamos del mal? Sería más lógico que la sociedad se intrigara frente a un entomólogo, un cantante de fados, un investigador de células madre. Pero no, en cuestión de interés morboso los polis estamos a la cabeza de la clasificación (Giménez Bartlett, 2009: 30-31).

Por ello, la proyección consustancial que de la Policía y de la Guardia Civil hacen tanto Silva como Giménez Bartlett, como baluartes de esta nueva novela policíaca, está basada en la documentación e instrucción minuciosa y veraz llevada a cabo por los escritores. A lo largo de estas dos series se procura un constante reflejo de diferentes situaciones verosímiles, susceptibles de asemejarse con totalidad a la realidad, donde los personajes literarios hilan y conducen todo ese mundo factible donde lo único ficticio son ellos mismos. No obstante, a pesar de esa precisa mímesis de la realidad, la trama continúa ajustándose al trazado tradicional, literario: los escritores respetarán las reglas del juego y el paradigma de la novela policíaca en la construcción argumental de sus historias.

A lo largo de estas series, los propios protagonistas (la inspectora Petra Delicado y el subinspector Fermín Garzón, para el caso de Giménez Bartlett; Rubén Bevilacqua y Virgnia Chamorro, para el del escritor madrileño) se esfuerzan en desmentir ideas obsoletas y desterrar prejuicios sociales para con su labor. Conscientes de la mala fama, de las reservas y suspicacias que arrastran, tratan de limpiar esta imagen a base de trabajo, de dosis de naturalismo, de carácter, de esfuerzo y de hábitos de costumbre. La mejor manera para acercarse al lector y tratar de despertar en este simpatía y complicidad hacia su oficio es mostrando acciones cotidianas, pasajes del día a día, heroicidades y hazañas, pero también los fracasos, las turbaciones y las decepciones, las interminables esperas o el tedio de la rutina.

En la permanente metaficción que realizan estas nuevas novelas policíacas, evocando convenciones tradicionales, se hace referencia al viejo y tópico carácter del detective novelesco, como si el personaje que la hace (Bevilacqua en este caso) no fuese también un policía ficticio:

Soy consciente de que investigar delitos por cuenta de la ley, y no a sueldo de un millonario o de una rica casquivana, como Philip Marlowe, es actividad poco propicia a los alardes creativos del investigador, y mucho menos el marco idóneo para esa autonomía que tanto le envidia el gris polizonte al carismático detective (Silva, 2014: 61). 
Policías y guardias: visión literaria en la nueva novela policíaca española

Tanto Giménez Bartlett como Silva acopian cuantiosos datos e informaciones, hablan, escuchan y toman de declaraciones y experiencias piezas para la construcción literaria. Ninguno de ellos elabora sus novelas según su noción de las prácticas o métodos investigadores, sino que ambos beben de fuentes directas y concretas para reconstruir con la mayor precisión y veracidad posible las aventuras de sus personajes. Por ello, los elementos que aparecen en las novelas, las situaciones, las técnicas, los trámites, los procedimientos, las relaciones jerárquicas, la organización o la estructura de la red policial concuerdan prácticamente en su totalidad con la realidad. Valgan los siguientes ejemplos, extraídos de estas series, para hacer ostensible la consideración social actual para con la idiosincrasia de policías y guardias, así como pasajes susceptibles de desarrollarse con facilidad en el mundo real que hoy estos habitan.

— ¿Usted se da cuenta de cómo es este país, Fermín? Aquí todo es sagrado y pasa por delante de la ley: el buen nombre y el honor, el orden interno de un convento, la familia... ¿Qué concepto tenemos los españoles sobre la policía? ¿Qué es lo que cree la gente, que nuestras investigaciones se llevan a cabo solo por joder al personal? Tal parece que fuéramos un adorno, un lujo superfluo.

- Ya se sabe, inspectora, que aquí nadie piensa que sirvamos realmente para nada. Hace ya unos cuantos años me dijo un vecino: «Y los objetos robados o drogas incautados en alguna acción que enseñan ustedes por la tele, ¿son de verdad o es más bien para demostrar que se ha hecho algo?». ¡Claro, imagínese el cabreo que me pesqué! (Giménez Bartlett, 2009: 267).

Asimismo, otro modo de referir con rigor formas y maneras de la Policía o de la Guardia Civil es rescatando escenas donde no prime la formalidad, quehaceres habituales o reacciones espontáneas del día a día. En esta ocasión, en la serie de Silva, este ejemplo es significativo precisamente por figurar una acción corriente de unos guardias civiles que, además de trabajar como tal, son también hombres que viven y conviven en la sociedad contemporánea, y que no son ajenos, por tanto, a lo que en ella se desarrolla.

Habíamos llegado ya junto al coche.

- Pues venga. Echando leches. Y que no os multen.

- ¿Y cómo se come lo uno con lo otro? - pregunté.

- Joder, ¿es que no sabes dónde están los radares, como cualquier conductor de este puto país? Lo que te digo es que ya estoy harto de mandarles oficios a los de Tráfico para justi- 
ficaros las urgencias y que os quiten las denuncias. Se chotean de mí. Me dicen que si tan mal organizamos nuestro trabajo que estamos siempre de urgencia (Silva, 2005: 18-19).

Esa concepción social de la ocupación del guardia civil o del policía se aprecia, también, en el temor ciudadano intrínseco que se remueve ante la presencia de un agente de la ley. Será de nuevo la resignación irónica y el humor, a menudo, la herramienta que estos enarbolen para rebajar situaciones más o menos tensas. La siguiente escena, protagonizada por el capitán Álamo, personaje secundario de la última novela de Silva a día de hoy, Lejos del corazón, es ejemplo de ello:

-Dile a tu jefe que ha llegado Leandro. No hace falta que sonrías, guapa, no vamos a gastarnos ni un euro aquí. Guardia Civil.

La recepcionista reemplazó al instante la amabilidad comercial por un rictus de horror.

Descolgó el teléfono, apretó un botón en la base y musitó a quienquiera que la escuchara al otro lado de la línea:

-Está aquí el señor Leandro...-dudó.

- Leandro verde que te quiero verde-dijo Álamo, impasible.

—...de la Guardia Civil_completó la chica mientras palidecía (Silva, 2018: 180).

Asimismo, el próximo diálogo advierte cómo a pesar de darse un considerable avance y modernización en las formas, internas y externas, de un cuerpo como la Guardia Civil - de sólida tradición militar - aún quedan reductos indisolubles de una mentalidad ya obsoleta, absurda y despótica. Bevilacqua persevera en la actualización, en la lucha contra esos viejos lastres que únicamente sirven para ralentizar, para avivar prejuicios y para dar la razón a aquellos que aún hoy sienten al guardia civil como un enemigo injusto y lleno de inquina. A pesar del empeño por sanear esta imagen, ignorar la existencia de quien aún piensa que el modo idóneo para hacerse respetar es a través del pavor y de la coacción, sería obviar la realidad.

-En fin, me esforzaré, por la cuenta que me trae. Pero me va a costar. En el destino del que vengo tenía un sargento primero que te arrestaba por llevar polvo en los zapatos.

-Es que la falta de cariño en la infancia puede llegar a ser muy mala. Tan solo espero que la experiencia con semejante espécimen no te haya traumatizado hasta el punto de impedirte ver que no todos los que llevamos galones sufrimos ese trastorno de la personalidad (Silva, 2010: 109).

En definitiva, estas dos series se alzan como ejemplo de esta corriente modernizadora del género. Ambas suponen la guía y el modelo que siguen, en su gran mayoría, 
los escritores que hoy en día se dedican a engrosar los títulos de novela policíaca. En aras del realismo presupuesto en este tipo de narraciones los sucesos, las escenas o las recreaciones vitales y profesionales pretenderán, siempre, asemejarse a esa realidad hasta la fecha desconocida y opaca de los policías y guardias de nuestro país. Esta identificación y normalización por parte del lector para con los personajes faculta una mayor cercanía entre realidad y ficción, siendo fácil confundir, a menudo, la segunda con la primera. Casi a modo de crónica lo narrado en estos libros presenta sucesos fácilmente identificables con noticias de prensa o con imágenes de telediario, con tramas conocidas o con problemáticas vigentes. A esto se suma el carácter humanizado de unos personajes renovados, concebidos a imagen y semejanza del hombre normal, cuya vida cotidiana no es extraordinaria, no posee dones ni capacidades sobrehumanas y su gran mérito es, únicamente, trabajar al servicio de la ley tratando de mantener a raya la injusticia, el abuso o la violencia. El detective es, en suma, un héroe moderno pero que se mueve por las razones y los valores más clásicos, históricos y legendarios: la lucha y defensa del bien frente al mal que amenaza el equilibrio del mundo. Ahora, sin embargo, no lo hace solo, pistola en mano y gabardina oscura, sino que se ampara en un escudo y en unos galones que representan y simbolizan a todo un país y a toda una sociedad.

\section{Bibliografía final}

Galindo, Juan Carlos, «20 años después, Bevilacqua y Chamorro siguen en plena forma», 2018, Recuperado de https://elpais.com/cultura/2018/05/28/elemental/1527511524_812305.html

Fecha de consulta: 7 de noviembre de 2018.

Giménez Bartlett, Alicia, Ritos de muerte, Barcelona, Ed. Planeta, 1996. , El silencio de los claustros, Barcelona, Ed. Destino, 2009.

Godón Martínez, Nuria, «La novela policíaca y Francisco García Pavón: la creación de un investigador manchego», Céfiro: Enlace Hispano Cultural y Literario, vol. V, n. ${ }^{\circ} 1-2,2005$, págs. 14-27.

Morán, David, «Novela policíaca española: detectives de pata negra», 2013, Recuperado de https://www.abc.es/cultura/libros/20130701/abci-detectives-201306302019.html

Fecha de consulta: 6 de noviembre de 2018.

Silva, Lorenzo, La reina sin espejo, Barcelona, Ed. Destino, 2005 , La estrategia del agua, Barcelona, Ed. Destino, 2010. , Los cuerpos extraños, Barcelona, Ed. Destino, 2014. , Lejos del corazón, Barcelona, Ed. Destino, 2018. 